\title{
A socio-hydrological comparative assessment explaining regional variances in suicide rate amongst farmers in Maharashtra, India
}

\author{
Nadja I. den Besten, Saket Pande, and Hubert H. G. Savenije \\ Department of Water Management, Delft University of Technolgy, Delft, the Netherlands \\ Correspondence to: Nadja I. den Besten (n.i.den.besten@student.tudelft.nl) \\ Published: 12 May 2016
}

\begin{abstract}
Maharashtra is one of the states in India that has witnessed one of the highest rates of farmer suicides as proportion of total number of suicides. Most of the farmer suicides in Maharashtra are from semi-arid divisions such as Marathwada where cotton has been historically grown. Other dominant crops produced include cereals, pulses, oilseeds and sugarcane. Cotton (fibers), oilseeds and sugarcane providing highest value addition per unit cultivated area and cereals and pulses the least. Hence it is not surprising that smallholders take risks growing high value crops without "visualising" the risks it entails such as those corresponding to price and weather shocks.

We deploy recently developed smallholder socio-hydrology modelling framework to understand the underlying dynamics of the crisis. It couples the dynamics of six main variables that are most relevant at the scale of a smallholder: water storage capacity (root zone storage and other ways of water storage), capital, livestock, soil fertility and fodder biomass. The hydroclimatic variability is accounted for at sub-annual scale and influences the socio-hydrology at annual scale. The model incorporates rule-based adaptation mechanisms (e.g., adjusting expenditures on food and fertilizers, selling livestocks) of smallholders when they face adverse conditions, such as high variability in rainfall or in agricultural prices.

The model is applied to two adjoining divisions of Maharashtra: Marathwada and Desh. The former is the division with relatively higher farmer suicide rates than the latter. Diverse spatial data sets of precipitation, potential evaporation, soil, agricultural census based farm inputs, cropping pattern and prices are used to understand the dynamics of small farmers in these divisions, and to attribute farmer distress rates to soil types, hydroclimatic variability and crops grown.

Comparative socio-hydrologic assessment across the two regions confirms existing narratives: low (soil) water storage capacities, no irrigation and poor access to alternative sources of incomes are to blame for the crisis, suggesting that smart indigenous solutions such as rain-water harvesting and better integration of smallholder systems to efficient agricultural supply chains are needed to tackle this development challenge.
\end{abstract}

\section{Introduction}

Smallholders contribute significantly to the total value of agricultural output in India, though their resilience to climate change and price volality make them susceptible to distress (Fan et al., 2013). The fragility of smallholders is very noticeable in farmer suicides rates in India. Between 1995 and 2012, approximately 284673 farmers committed suicide in several regions in India, with a peak in 2006 and 2010 (Nagaraj, 2008; Mishra, 2014).

Understanding the challenges encountered by (small) farm holders requires a multi-disciplinary approach. The following research builds upon Pande and Savenije (2016) to explain smallholder dynamics between its natural resources and socio-economic situation within a water-centric approach. We zoom into the state of Maharashtra where one of the highest rates of suicide amongst farmers have been recorded 


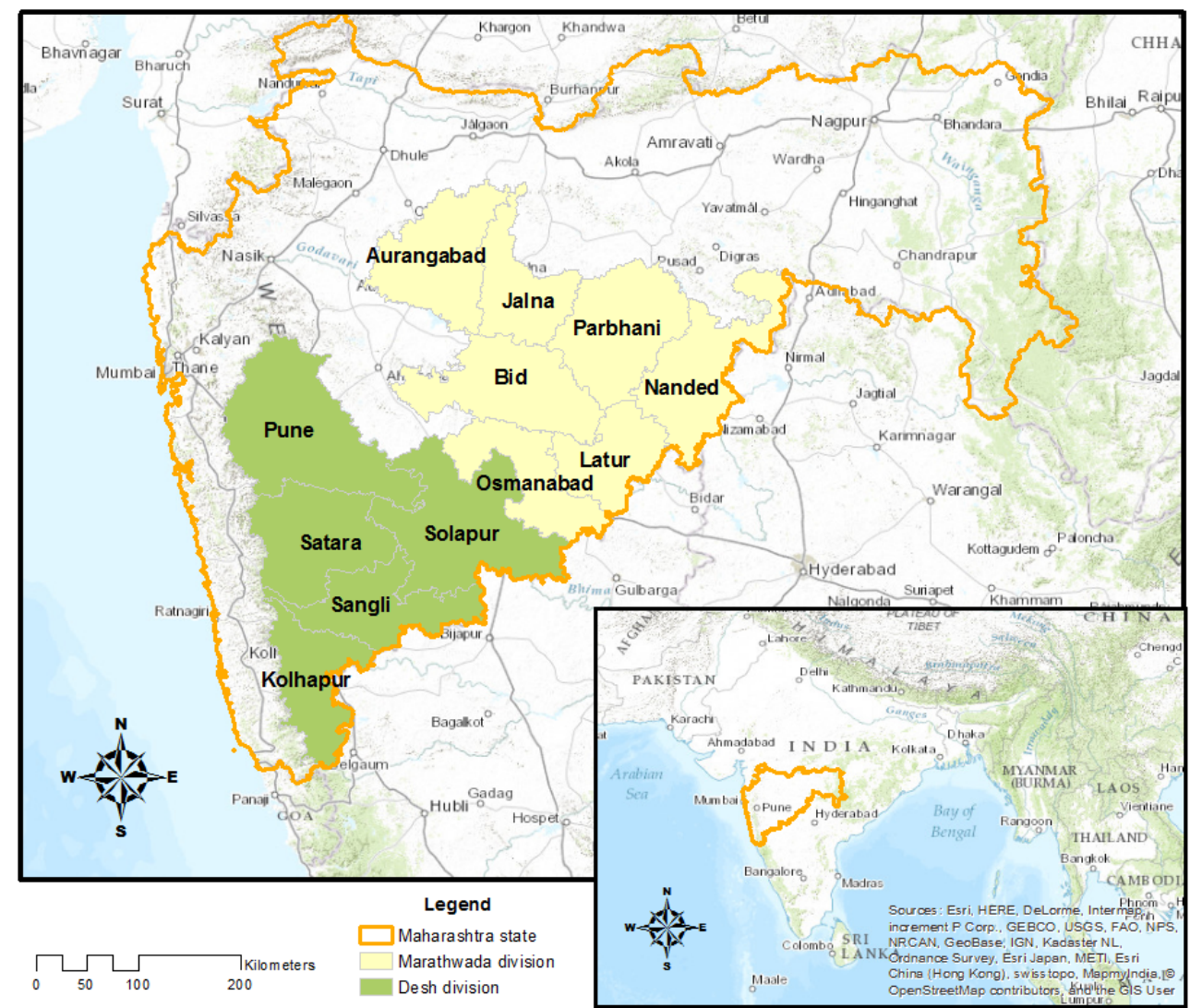

Figure 1. Location of simulated districts. Model simulations for the following eleven districts were conducted in Maharashtra, the districts in Marathwada: Aurangabad, Beed, Jalna, Latur, Osmanabad, Parbhani, and the districts in Desh: Pune, Sangli, Satara, Solapur and Kholapur. Spatial variable data sets on potential evaporation, soil properties and rainfall were weighted on district level.

(NCRB, 2014). The socio-hydrological modelling framework is applied to two regions of Maharashtra: Marathwada and Desh (see Fig. 1). We examine small farmers with 14 ha of ground. The agricultural income mainly depends on cotton and sugarcane production. Besides these crops, jowar (Sorghum), rice and soybean cultivation are also abundant. Near to sixty percent of the smallholders in the regions under study produce these five crops (Agriculture Census Division, 2011).

Marathwada division has experienced relatively higher farmer suicide rates than Desh (Ramanna, 2006; Khairnar et al., 2015). The aim of this paper is to explain this difference between the two sub-divisions through comparative assessment of smallholder socio-hydrological model simulations in terms of differences in hydro-climatic variability, soil heterogeneity and types of crops grown.

\section{Methodology}

The smallholder socio-hydrologic modelling framework proposed by Pande and Savenije (2016) is a dynamic model that can be made location specific. It consists of six sociohydrological state variables: soil moisture, soil fertility, cap- ital, livestock, fodder and labor availability. All these state variables are modelled by simple differential equations. Seven socio-hydrologic flux variables determine the interrelationships between these state variables, these are: crop production, livestock sales, expenditure, livestock production costs, crop production costs, labor factor and fertilizer factor. Climatic forcing and wage rate are external to the smallholder model system and influence the system as such.

To explain the modelling framework in a nutshell, consider a small farmer experiencing a year with disappointing crop yields due to poor rainfall, e.g. his/her capital encounters deficits as a result and therefore the farmer cuts down on his/her expenditure by selling livestocks, cutting down on investments, school fees and so on. The farmer stops cutting down on his/her expenditure when capital becomes positive again. These adjustments consequently affect the sociohydrological state variables for the next year. The evolution of farmers capital thus depends on how much he or she is exposed to hydro-climatic variability (that affects crop yields) and price volatility (that affects crop income) and whether the farmer has access to hydrologic or financial instruments that can buffer these variabilities. 
Table 1. Transpiration demand not met, gives the percentage of mean annual transpiration demand that is not met when rainfall is not enough to sustain crop water demand during growing season. The values in the brackets display the average yearly values of these deficits in $\left[\mathrm{mm} \mathrm{yr}^{-1}\right]$ over the simulated time (1983-2009). \% rainwater buffer: gives the percentage of years when the amount of annual rainfall was not enough to sustain transpiration demand, and consequently it gives the percentage of years when harvesting rainwater was not a sufficient strategy.

\begin{tabular}{|c|c|c|c|c|}
\hline \multirow[t]{2}{*}{ Crops } & \multicolumn{2}{|c|}{ Marathwada } & \multicolumn{2}{|l|}{ Desh } \\
\hline & $\%$ transpiration demand deficit & $\%$ rainwater buffer & $\%$ transpiration demand deficit & $\%$ rainwater buffer \\
\hline Sugarcane & $84\left[-1080 \mathrm{~mm} \mathrm{yr}^{-1}\right]$ & 63 & $77\left[-945 \mathrm{~mm} \mathrm{yr}^{-1}\right]$ & 53 \\
\hline Jowar & $31\left[-70 \mathrm{~mm} \mathrm{yr}^{-1}\right]$ & 29 & $22\left[-50 \mathrm{~mm} \mathrm{yr}^{-1}\right]$ & 15 \\
\hline Cotton & $50\left[-220 \mathrm{~mm} \mathrm{yr}^{-1}\right]$ & 53 & $45\left[-200 \mathrm{~mm} \mathrm{yr}^{-1}\right]$ & 30 \\
\hline Rice & $89\left[-285 \mathrm{~mm} \mathrm{yr}^{-1}\right]$ & 80 & $65\left[-180 \mathrm{~mm} \mathrm{yr}^{-1}\right]$ & 49 \\
\hline Soybean & $44\left[-120 \mathrm{~mm} \mathrm{yr}^{-1}\right]$ & 35 & $37\left[-100 \mathrm{~mm} \mathrm{yr}^{-1}\right]$ & 19 \\
\hline
\end{tabular}

\subsection{Input data and parameters}

The dominant soil types in the study regions were obtained through the Harmonized World Soil Database v1.2 (Fischer et al., 2008). All dominant soil textures throughout Marathwada and Desh are classified as loamy to clayey textures (USDA Texture classification) in the subsoil (Fischer et al., 2008). We assume that Available Water Storage Capacity (AWSC) is $175 \mathrm{~mm} \mathrm{~m}^{-1}$ for loam and $200 \mathrm{~mm} \mathrm{~m}^{-1}$ for clay. The soil water storages for every district are then calculated by weighted mean soil depth (India-WRIS WebGIS, 2016) of the districts multiplied by the previously mentioned AWSC.

Precipitation and potential evaporation data-series are created based on satellite products provided by Jones and Harris; Zomer et al. (2008). Freely available Global Potential Evapo-Transpiration (Global-PET) with a spatial resolution of $30 \operatorname{arcsec}(\sim 1 \mathrm{~km}$ at equator) is used to compute average potential evaporation on district level. The product used provides monthly averages over the years 1950-2000. These monthly averages are assumed to represent the potential evaporation over the simulated years. For precipitation a coarser product from the CRU-TS 3.0 Climate Database, with a $0.5^{\circ}(30 \mathrm{arcmin})$ spatial resolution on land areas, is used.

Fertilizer and crop prices are obtained from The Worldbank (2010) with an exchange rate of Rs $45=$ USD 1 to convert The Worldbank (2010) prices to Rs per kilogram. Crop specific yield coefficients are obtained as described by FAO (2015). Assumed application of fertilizers is as follows: $27 \mathrm{kgNha}^{-1}$ for Jowar, $57 \mathrm{kgNha}^{-1}$ for Paddy and $10 \mathrm{kgNha}^{-1}$ applied for soybean production (FAO, 2005). The three crops are modelled as Kharif crops, growing from June until maximum October. All the crop factors have been obtained from FAO (FAO, 2015).

\section{Results}

Marathwada is climatologically different from Desh: $860 \mathrm{mmyr}^{-1}$ of rainfall falls on average in Marathwada, while Desh approximately receives $1000 \mathrm{~mm} \mathrm{yr}^{-1}$. The Solapur district within Desh that neighbours Marathwada is drier compared to other districts in Desh. Rain-fed agriculture is dominant in the districts under study (except under sugarcane production), therefore the water demands (crop transpiration) and supplies (rainfall) are analysed among all crops in the study area (Table 1).

The soil depths are highly variable within the study area. Shallow soils $(0-25 \mathrm{~mm})$ are primarily located in various districts of Marathwada, resulting in a disadvantage in average soil water storages for Marathwada compared to the region of Desh. The shallow soils limit the rooting depths of the crops grown in the area (Letey, 1985), hence decreasing estimated soil storage capacities.

The estimated soil water storages and district specific hydroclimatic forcing were used to simulate the effect on smallholder's capital and shown in Fig. 2.

\section{Discussion}

Marathwada is faced with higher suicide rate than the region of Desh. With the help of the water-centric approach within the socio-hydrological modelling framework, we tested a hypothesis that inclusion of spatial heterogeneity within the model can explain the differences in well-being of smallholders between the two regions. This is in addition to observed differences in hydro-climatic variability between the two regions. These outcomes suggest that high hydro-climatic variability, shallow soils and poor (risky) crop choices made by smallholders, can explain higher suicide rates in Marathwada. From Fig. 2 one can see that crop income falls in Marathwada when suicide rates start to rise. This indicates that Marathwada might contribute to the distress that farmers are facing in Maharashtra. 


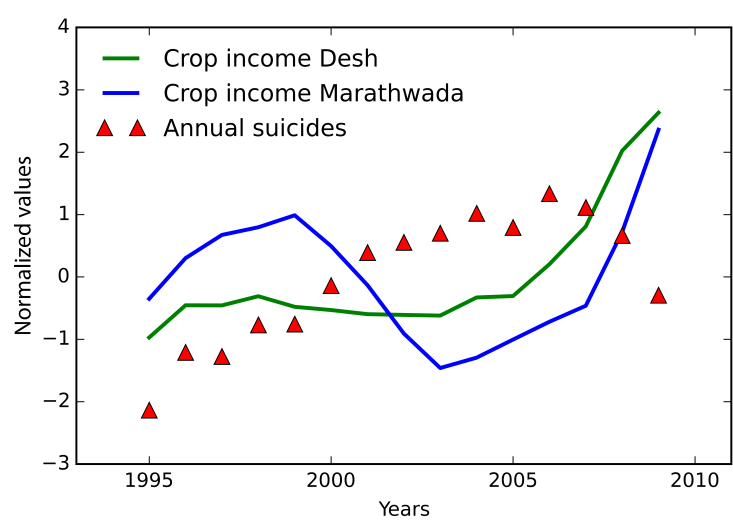

Figure 2. The capital (model) outcomes for all crops in all districts within a given sub-division (i.e. Desh and Marathwada) under study were aggregated based on agricultural census data on smallholders. Crop area weighted mean capital time series were estimated for the two divisions. Suicide rates at state level (Maharashtra) are plotted to indicate distress amongst farmers within the state. All 3 time series were normalized by substracting the mean and dividing by the standard deviation

Comparing hydro-climatological, soil characteristics and crops grown between the divisions one can see that the characteristics are unfavourable for Marathwada. Table 1 displays that the need to overcome crop transpiration demand deficits is higher in Marathwada than in the division of Desh. Further, even rainwater harvesting in Marathwada is not as successful as in Desh.

High water demanding crops such as cotton are generally favoured in Marathwada (24\% of the smallholders), while in Desh only $0.6 \%$ of the smallholders choose to grow cotton primarily under rain-fed condition. Taking into account the observations in Table 1, creating local storages in Marathwada will not be enough to bridge monthly deficits during a growing season. A combination of solutions is indeed needed to outweigh unfavourable farming conditions in Marathwada. The policy and interventions in such regions could be steered in the direction of (1) preventing farmers from betting on a good monsoon and deciding to high risk crops in inadequate locations, and (2) to invest in local storages where biophysical characteristics (as soil depth e.g.) are adequate.

\section{Data availability}

The spatial distribution of soils was analyzed with a data set available at the repository of World Data Centre for Soils, re3data.org.

\section{References}

Agriculture Census Division: Agricultural Census Data Base, available at: http://agcensus.dacnet.nic.in/, last access: 20 December 2015, 2011.

FAO: Fertilizer use by crop in India, Tech. rep., Food and Agriculture Organization of the United Nations (FAO), Viale delle Terme di Caracalla, Rome, Italy, 2005.

FAO: Crop Water Information, available at: http://www.fao.org/nr/ water/c, last access: 11 January 2016, 2015.

Fan, S., Brzeska, J., Keyzer, M., and Halsema, A.: From subsistence to profit: Transforming smallholder farms, International Food Policy Research Institute (IFPRI), Tech. rep., 30 pp., 2013.

Fischer, G., Nachtergaele, F. O., Prieler, S., Teixeira, E., Tóth, G., van Velthuizen, H., Verelst, L., and Wiberg, D.: Global Agroecological Zones Assessment for Agriculture (GAEZ 2008), IIASA, Laxenburg, Austria and FAO, Rome, Italy, 2008.

India-WRIS WebGIS: Soil depth, available at: http://india-wris. nrsc.gov.in/soilapp.html, last access: 10 January 2016.

Jones, P. D. and Harris, I.: Climatic Research Unit (CRU) timeseries datasets of variations in climate with variations in other phenomena, NCAS British Atmospheric Data Centre, Harwell Oxford, 2013

Khairnar, D. R., Bhosale, M. J., and Jadhav, M. A.: Lack of irrigation facilities, drought conditions and farmers suicides in Marathwada region, India, American Journal of Rural Development, 3 , 74-78, 2015.

Letey, J.: Relationship between soil physical properties and crop production, in: Advances in soil science, Springer, 1, 277-294, doi:10.1007/978-1-4612-5046-3_8, 1985.

Mishra, S.: Farmers' suicides in India, 1995-2012: measurement and interpretation, Asia Research centre, London, 2014.

Nagaraj, K.: Farmers' suicides in India: magnitudes, trends and spatial patterns, 4th Edn., Bharathi puthakalayam, 421, Anna Salai, Teynampet, Chennai, 2008.

Pande, S. and Savenije, H. H.: A sociohydrological model for smallholder farmers in Maharashtra, India, Water Resour. Res., 52, doi:10.1002/2015WR017841, online first, 2016.

Ramanna, A.: Farmers rights in India: a case study, Tech. Rep. 4, The Fridtjof Nansen Institute, available at: http://www. mtnforum.org/sites/default/files/publication/files/4046.pdf, last access: 15 January 2016, 2006.

re3data.org: Registry of Research Data Repositories, re3data.org doi:10.17616/R3X01J, last access: 26 April 2016.

Zomer, R. J., Trabucco, A., Bossio, D. A., and Verchot, L. V.: Climate Change Mitigation: A Spatial Analysis of Global Land Suitability for Clean Development Mechanism Afforestation and Reforestation, Agr. Ecosyst. Environ., 126, 67-80, 2008. 